IFN Working Paper No. 865, 2011

\title{
Growth Effects of Fiscal Policies: A Critical Appraisal of Colombier's (2009) Study
}

Andreas Bergh and Nina Öhrn 


\title{
GROWTH EFFECTS OF FISCAL POLICIES: A CRITICAL APPRAISAL OF COLOMBIER's (2009) STUdY*
}

\author{
Andreas Bergh ${ }^{1,2}$ and Nina Öhrn ${ }^{1}$
}

February 11, 2011

\begin{abstract}
In a recent paper, Colombier (2009) uses a robust estimation technique and claims to find empirical evidence that government size has not been detrimental to growth for OECD countries during the 1970 to 2001 period, and that endogenous growth theory is not corroborated. We examine the robustness of these findings, and show that Colombier's results differ from those in other recent papers not because of the estimator used, but because of the exclusion of other control variables. Adding time fixed effects to Colombier's data set, and using the same econometric method, we obtain results in line with other findings, corroborating endogenous growth theory. Adding further control variables illustrates the robustness of the negative correlation between total tax revenue and economic growth for both instrumented and noninstrumented regressions.
\end{abstract}

JEL classification: E62, H11, H20, O43

Keywords: Economic growth, Government size; Taxation, Robust estimators, Panel data

\author{
${ }^{1}$ Research Institute of Industrial \\ Economics (IFN) \\ Box 55665 \\ SE-102 15 Stockholm \\ e-mail: nina.ohrn@ifn.se
}

\author{
${ }^{2}$ Deptartment of Economics, \\ Lund University \\ P.O. Box 7082 \\ SE-220 07 Lund \\ e-mail: andreas.bergh@ifn.se
}




\section{Introduction}

This article examines the recent paper by Colombier (2009), which claims that government size has not been detrimental to growth for OECD countries in the past, and that endogenous growth theory, suggesting that distortionary taxation decreases growth, is not corroborated. For those who have followed the debate regarding the relationship between government size and economic growth, the paper by Colombier (2009) differs both in the method used and in the results presented.

Colombier uses a robust modified M-estimator to argue that several other papers have mistakenly concluded that the correlation between aggregate government size and annual growth of real GDP per capita has been negative since around 1970 among OECD-countries. In the abstract of the article, Colombier concludes that aggregate government size has not been detrimental for OECD-countries in the past, and in the concluding section, Colombier claims that "[i]n contrast to recent studies, this analysis finds a stable positive, albeit small, growth effect of government size." If Colombier's finding is correct, a number of other recently published studies are wrong. It is therefore of great importance to examine why Colombier's results are the opposite of what other scholars have found. The message sent by Colombier is that the more appropriate robust estimator is responsible for the unusual results, but there are several other possible explanations in addition to the estimator used: Colombier uses a design with moving averages which is not often seen in this type of research, he includes relatively few other control variables in his analysis and he refrains from using time fixed effects.

In this note, we show that Colombier's results are not driven by the specific econometric technique used, but rather driven by the omission of time fixed effects and other control variables. In fact, when adding year fixed effects, Colombier's method and Colombier's data support the typical conclusion in this line of research: a negative and often highly significant correlation between government size and growth.

\section{Related literature}

Colombier is aware that finding a positive correlation between government size and growth is in contrast with other studies. He rightly notes that Fölster and Henrekson (2001) and De Avila and Strauch (2003) come to the opposite conclusion, but he maintains that "the majority of recent studies suggest no growth effects of government size" (p. 910). To support this claim he refers to four studies: Kneller et al. (1999), Bassanini et al. (2001), Bleaney et al. (2001) and Agell et al. (2006).

Colombier's description of existing literature leaves room for improvement. First of all, the reference to Kneller et al. (1999) is misleading. The issue analyzed in this paper is not the correlation between aggregate government size and growth, but rather the growth effects of different types of taxes and expenditure, thereby testing and confirming endogenous growth theory. The study finds that 
distortionary taxation reduces growth, whilst non-distortionary taxation does not, and also that productive government expenditure enhances growth, whilst non-productive expenditure does not. The paper by Bleaney, et al. (2001) is written by the same authors and analyzes the same questions using the same data and reaches the same conclusion. The correlation between aggregate government size and growth is not tested in any of these two papers.

Secondly, the reference to the OECD-working paper by Bassanini et al. (2001) is in some sense more appropriate, as this paper actually tests the question at stake. This paper, however, finds a large and significant negative correlation between aggregate government size and growth. Commenting on their results, the authors write:

The hypothesis that the size of government has an impact on growth receives some qualified support (Table 5). [...] The overall tax burden is estimated to have a negative impact on output per capita and, controlling for the overall tax burden, there is an additional negative effect coming from a tax structure focusing on direct taxes. (p. 28-29)

Colombier's fourth and final example is the paper by Agell, et al. (2006), which is a critique of the Fölster and Henrekson (2001) paper. Agell et al. argue that the negative correlation found by Fölster and Henrekson cannot be given a causal interpretation and that the results are not robust to first difference estimation and some country exclusions. In total, Colombier mentions four papers to support his proposition that "the majority of recent studies suggest no growth effects of government size". Two of these four papers analyze a different question, and one of the four finds the opposite of what Colombier claims. Only the paper by Agell et al. gives some support to Colombier's view.

Moreover, a number of papers not mentioned by Colombier have recently examined the correlation between growth and government size. In addition to Fölster and Henrekson (2001), papers by Dar and AmirKhalkhali (2002), Romero-Avila and Strauch (2008), Bergh and Karlsson (2010) and Afonso and Furceri (2010) all find a statistically and economically significant negative correlation between aggregate government size and growth in rich countries. The omission of the latter two can of course be explained by them being published later, but the main impression is nevertheless that Colombier is not fully accurate in his description of existing literature.

\section{A Robustness test of Colombier's results}

Colombier states that the aim of his study is two-fold: to analyze growth effects of fiscal policies and to show that robust estimation methods are superior to least square estimators in the analysis. This is indeed a relevant research question, as it is well-known that ordinary least squares (OLS) estimation is highly sensitive to outliers. The problem arises because OLS minimizes the sum of squared errors, which assigns excessive importance to large residuals. 
In our view, Colombier is right to argue that the results in the literature on the relationship between government size and growth should be tested by applying a robust method. Great care has been taken in the literature to examine the stability of results to the inclusion of different control variables, different countries and time periods, as well as to mitigate potential problems of reversed causality between government size and growth. As rightly argued in the article, however, outliers may be a serious problem in any econometric study.

Given that outliers have been detected in the sample (which is a problem in itself), it is not clear-cut what to do with them. Removal of outliers work if one can establish that there is an error in the making of the observation, but if this is not the case, removal of outliers decreases the dispersion present in the data, shrinks the standard errors of estimates and leads to shaky inference. Rather than treating outliers in a way that either includes them or assigns them equal weight as to the rest of the observations, robust methods present systematic ways of including the atypical observations in the regression framework by assigning them less weight in the estimation.

Formally speaking, the breakdown point of an estimator is the maximum fraction of outliers tolerated in a given sample before the estimate is completely flawed (Huber, 1981). OLS has a breakdown point of zero. As a remedy, several robust regression methods (methods with breakdown points larger than zero) exist, but early methods suffered from low efficiency compared to OLS. ${ }^{1}$ The method applied by Colombier is the MM-estimator developed in Yohai (1987), which combines a high breakdown point (0.5) with high efficiency (in this case $95 \%$ of that of ordinary least squares, achieved in the case where residuals are Gaussian). The MM-estimator minimizes the residuals scaled by a loss function $\rho$, which is less increasing than the square function for large residuals. ${ }^{2}$

In a panel data analysis, the researcher is generally interested in the most coherent part of the sample. One can also expect to find outlier clusters in panel data, representing individual countries or time periods. Country- and time period fixed effects in a least squares panel data regression also assess these problems by allowing individual intercepts and/or slopes for different countries and time periods, but OLS assigns equal weight to all observations when fitting the regression line. Country- and time period fixed effects can also be incorporated in robust methods, but in addition to allowing for different intercepts the robust methods also scales down the importance of observations which are atypical once observable factors are controlled for.

\footnotetext{
${ }^{1}$ For descriptions of robust methods, see Rousseeuw (1984) for the least median of squares, Rousseeuw and Yohai (1984) for the S-estimators and Yohai (1987) for MM-estimators.

${ }^{2}$ Formally, the function $\rho$ (.) must be even, non-decreasing in the residuals and less increasing than the square function. Residuals are also scaled by a measure of dispersion in order to assure independence with respect to the measurement units of the dependent variable. A common choice of $\rho$ is the Tukey's Biweight function.
} 
Colombier's theoretical basis is an endogenous growth model, where growth in GDP per capita is explained by the growth rate of the labor force, the investment rate as a share of GDP and a government sector. The government sector is measured as taxes, government revenue and government expenditure, all in relation to GDP. No control variables besides fixed effects for countries are included.

As mentioned earlier, the robust regression method is not the only new feature in the article. First, the estimated model only includes three variables and country fixed effects, which leads to the suspicion of omitted variable bias. Second, other papers typically use five year averages of the data, whereas Colombier uses a moving average specification. Third, no time-period fixed effects are included in the model. This is problematic because growth rates across countries react similarly to common shocks, and time period fixed effects are usually included to accommodate this. Given all these differences from how the question is usually analyzed in the literature, it is difficult to establish if the new result is due to the new estimation technique or due to any of the other differences.

The MM-estimator is rather computer-intensive, and inclusion of many variables is problematic in this respect, but since economic growth is highly sensitive to global trends, the exclusion of time-period fixed effects may severely bias the results. Because the method is computationally intensive, we use the STATA command mmregress (Vincenzo and Croux, 2009) which requires far less iteration than the full MM-estimator. Running a few estimations with all iterations does not change our results, and using the faster approach allows us to include time fixed effects as well as to test the robustness of Colombier's results in a number of ways.

\section{Data}

The estimation is made following the procedure outlined in Colombier's article and using the same dataset. The dataset covers 21 OECD-countries over the period 1970 to 2001, and is collected from the OECD Economic Outlook No. 74. To this data we also add data for the share of total population in the age group 16-64 years old, also taken from the OECD Economic Outlook No. 74. From the Penn World Tables (Heston et al, 2009) we use data for imports and exports (both in relation to GDP), the unemployment rate and the annual inflation rate. During our replication, we discovered that the investment data is purified by Colombier before entering the regression, using a procedure not explained in the original article. ${ }^{3}$

\footnotetext{
${ }^{3}$ The purifications used by Colombier involves regressing gross investment on the labor force, a set of variables for public investment and country dummies. The residual from this regression then enter the growth regression.
} 
To discuss and identify possible endogeneity problems, Colombier runs both instrumented and noninstrumented regressions. Fiscal variables are instrumented by the variable itself lagged five years. The most obvious problem of endogeneity is that social insurance schemes in welfare states act as automatic stabilizers. For this reasons expenditure will be high as a result of lower economic growth. In addition to running instrumented regressions, this is often viewed as a reason to put more weight on estimates for tax revenue, as the bias here runs in the opposite direction: When growth is high, tax revenue will be higher due to progressive taxes and taxes on capital gains. As discussed by for example by Romero-Avila and Strauch (2008), a negative coefficient on taxes therefore provides rather strong evidence that high taxes cause lower growth, because reverse causality leads us to expect a positive correlation.

\section{Results}

Having assessed the robustness of Colombier's results in a number of ways, we have found that the non-standard results can be fully explained by Colombier's limited inclusion of control variables, most crucially the omission of time-period fixed effects. In contrast, Colombier's use of the MM-estimator, purification of the investment variable and different ways of calculating the moving averages seem unimportant for the results.

Tables $1 \mathrm{a}$ and $1 \mathrm{~b}$ illustrates the result of adding time fixed effects to the regressions presented by Colombier. In both tables, columns 1 and 3 are Colombier's estimates, and in column 2 and 4 we add time fixed effects to the estimation. ${ }^{4}$ As can be seen, time fixed effects change the results completely: Total government revenue changes from being positive and insignificant to negative and significant. The negative coefficient on expenditure becomes more negative.

\footnotetext{
${ }^{4}$ In all tables, we report standard errors which are robust to autocorrelation and heteroskedasticity. The derivation of standard errors is given in Croux, Dhaene and Hoorelbeke (2008).
} 
Table 1a. Adding time period fixed effects to non-instrumented regressions

\begin{tabular}{lllll}
\hline & $(1)$ & $(2)$ & $(3)$ & $(4)$ \\
\hline Labor force & $0.347^{* *}$ & $0.526^{* *}$ & $0.381^{*}$ & $0.393^{* *}$ \\
& $(0.236)$ & $(0.204)$ & $(0.196)$ & $(0.156)$ \\
Investment & $0.091^{* * *}$ & 0.005 & $0.099^{* * *}$ & -0.027 \\
& $(0.033)$ & $(0.024)$ & $(0.035)$ & $(0.027)$ \\
Revenue & 0.023 & $-0.122^{* * *}$ & & \\
Expenditure & $(0.025)$ & $(0.025)$ & & $-0.085^{* * *}$ \\
Constant & $1.498^{*}$ & $7.489 * * *$ & $4.036^{* * *}$ & $7.159 * * *$ \\
& $(0.860)$ & $(1.220)$ & $(1.202)$ & $(1.158)$ \\
\hline Observations & 380 & 507 & $-0.075^{* * *}$ & $(0.017)$ \\
Scale & 0.330 & 0.596 & 0.420 & 0.566 \\
Country FE & Yes & Yes & Yes & Yes \\
Year FE & No & Yes & No & Yes
\end{tabular}

Notes: Dependent variable: growth rate of GDP per capita in PPP. Period: 1970-2001. Columns 1 and 3 are the results presented in Colombier (2009), Standard errors robust to autocorrelation and heteroskedasticity in parentheses. $* * * \mathrm{p}<0.01$, $* * \mathrm{p}<0.05, * \mathrm{p}<0.1$

Table 1b. Adding time period fixed effects to instrumented regressions

\begin{tabular}{lllll}
\hline & $(1)$ & $(2)$ & $(3)$ & $(4)$ \\
\hline Labor force & $0.499 * *$ & 0.054 & $0.467 * *$ & 0.181 \\
& $(0.236)$ & $(0.155)$ & $(0.224)$ & $(0.177)$ \\
Investment & $0.057 *$ & $-0.057 * *$ & $0.073^{* *}$ & -0.022 \\
& $(0.033)$ & $(0.027)$ & $(0.034)$ & $(0.033)$ \\
Revenue & $0.068^{* * *}$ & $-0.085^{* * *}$ & & \\
Expenditure & $(0.025)$ & $(0.024)$ & & \\
Constant & -1.188 & $6.329 * * *$ & $-1.645^{* *}$ & $3.327 * * *$ \\
& $(0.808)$ & $(1.259)$ & $(0.711)$ & $(1.068)$ \\
\hline Observations & 338 & 433 & 352 & 468 \\
Scale & 0.300 & 0.534 & 0.300 & 0.570 \\
Country FE & Yes & Yes & Yes & Yes \\
Year FE & No & Yes & No & Yes
\end{tabular}

Notes: Dependent variable: growth rate of GDP per capita in PPP. Period: 1970-2001. Fiscal variables are instrumented by the variable itself lagged 5 years. Columns 1 and 3 are the results presented in Colombier (2009). Standard errors robust to autocorrelation and heteroskedasticity in parentheses. ${ }^{* * *} \mathrm{p}<0.01,{ }^{* *} \mathrm{p}<0.05,{ }^{*} \mathrm{p}<0.1$ 
Colombier also examines the growth effects of different types of taxes separately. Table 2 replicates these results, adds time fixed effects and also shows the effects of adding additional control variables to the analysis. For additional controls, we focus on three of the most commonly included variables, namely the unemployment rate, the annual inflation rate and economic openness, the latter measured as the sum of imports and exports over GDP. The control variables are not mainly added because we are interested in, say the causal effect of a higher unemployment rate on the growth rate of the economy, but rather in order to decrease dispersion in the data. Having few variables in the model or omitting variables which are highly correlated with the dependent variable increases standard errors and give inconsistent estimates. Failure to include important determinants of the dependent variable may also create additional outliers.

Table 2. Adding more variables to the specification: instrumented regressions

\begin{tabular}{|c|c|c|c|c|c|c|c|c|c|c|}
\hline & (1) & (2) & (3) & (4) & (5) & (6) & (7) & (8) & (9) & (10) \\
\hline \multirow[t]{2}{*}{ Labor force } & $0.617 * * *$ & 0.258 & 0.033 & 0.019 & 0.031 & 0.467 ** & 0.181 & -0.223 & -0.140 & -0.178 \\
\hline & $(0.227)$ & (0.174) & $(0.163)$ & $(0.147)$ & $(0.150)$ & $(0.224)$ & $(0.177)$ & $(0.234)$ & $(0.183)$ & $(0.157)$ \\
\hline \multirow[t]{2}{*}{ Investment } & $0.107 * * *$ & -0.007 & 0.011 & & & $0.073^{* *}$ & -0.022 & -0.029 & & \\
\hline & $(0.036)$ & $(0.026)$ & $(0.044)$ & & & $(0.034)$ & $(0.033)$ & $(0.047)$ & & \\
\hline \multirow[t]{2}{*}{ Tax goods } & $0.295^{* * *}$ & 0.068 & $-0.114^{*}$ & $-0.114^{*}$ & $-0.188 * * *$ & & & & & \\
\hline & $(0.104)$ & $(0.057)$ & $(0.061)$ & $(0.060)$ & $(0.057)$ & & & & & \\
\hline \multirow[t]{2}{*}{ Tax income } & -0.032 & $-0.072 * *$ & $-0.094 * *$ & $-0.092 * *$ & $-0.079 * *$ & & & & & \\
\hline & $(0.055)$ & $(0.033)$ & $(0.038)$ & $(0.037)$ & $(0.036)$ & & & & & \\
\hline \multirow[t]{2}{*}{ Expenditure } & & & & & & $0.056^{* * *} *$ & -0.015 & $0.035^{* *}$ & 0.032 & 0.001 \\
\hline & & & & & & $(0.010)$ & $(0.013)$ & $(0.016)$ & $(0.026)$ & $(0.020)$ \\
\hline \multirow[t]{2}{*}{ Openness } & & & $0.080^{* * *}$ & $0.079 * * *$ & $0.062 * * *$ & & & $0.065 * * *$ & $0.067 * * *$ & $0.065 * * *$ \\
\hline & & & $(0.014)$ & $(0.012)$ & $(0.011)$ & & & $(0.011)$ & $(0.010)$ & $(0.011)$ \\
\hline \multirow[t]{2}{*}{ Inflation } & & & $-0.161 * * *$ & $-0.160^{* * *}$ & $-0.175^{* * *}$ & & & $0.233 * * *$ & -0.230 *** & $-0.179 * * *$ \\
\hline & & & $(0.022)$ & $(0.022)$ & $(0.023)$ & & & $(0.021)$ & $(0.024)$ & $(0.027)$ \\
\hline \multirow[t]{2}{*}{ Unemployment } & & & $-0.075^{* *}$ & $-0.080 * *$ & & & & $-0.120 * * *$ & $-0.107 * * *$ & \\
\hline & & & $(0.035)$ & $(0.032)$ & & & & $(0.032)$ & $(0.027)$ & \\
\hline \multirow[t]{2}{*}{ Constant } & 0.145 & $1.980 * *$ & 1.097 & 1.425 & $3.481 * * *$ & $-1.645^{* *}$ & $3.327 * * *$ & 0.125 & -0.488 & 0.503 \\
\hline & $(0.916)$ & $(0.935)$ & (1.771) & (1.239) & (1.194) & $(0.711)$ & (1.068) & (1.383) & $(0.937)$ & (1.401) \\
\hline Observations & 357 & 451 & 384 & 384 & 450 & 352 & 468 & 391 & 391 & 467 \\
\hline Scale & 0.360 & 0.602 & 0.499 & 0.520 & 0.517 & 0.300 & 0.570 & 0.463 & 0.477 & 0.505 \\
\hline Year FE & No & Yes & Yes & Yes & Yes & No & Yes & Yes & Yes & Yes \\
\hline
\end{tabular}

Again, adding year fixed effects is sufficient for most results to look completely standard. The positive coefficient on taxes on goods becomes insignificant whereas the coefficient on income taxes turns significantly negative. Adding additional controls illustrates the robustness of the latter effect. For expenditure, results are less stable and in one case (column 8) a small but significant growth effect of public expenditure shows up even with year fixed effects included. Note also that all control variables 
have the expected sign and are highly significant: Inflation and unemployment correlate negatively with growth, while openness is positively correlated with growth. In all, these results are very much in line with similar recent studies, such as Bergh and Karlsson (2010). ${ }^{5}$

Finally, we also examine how results change when changing the calculation of moving averages. Averages are usually used to mitigate problems of reversed causality as business cycle fluctuations may cause changes in government expenditure and revenue through the working of automatic stabilizers. Smoothed data should work just as well as data partitioned into five-year periods, which is common in the literature. Our replications (not shown) indicate that results are not very sensitive to different ways of calculating moving average smoothing of the data.

\section{Concluding discussion}

Colombier's central claim is that the robust regression method gives new insights on the relationship between government size and growth. While there are good reasons to use a robust estimator, it does not seem warranted to argue that it gives new insights. On the contrary, once year fixed effects are included, results look very much as expected, given what similar studies have found.

Regardless of the result, it is interesting to note that Colombier elaborate much on the reasons why standard results are seemingly reversed when using a robust estimator. Such a result would mean that previous research is flawed due to one or a few outliers, in which case it would be motivated to investigate these further. Some outliers should be disregarded due to measurement errors or known extraordinary circumstances, while other outliers should properly be included in the sample despite being far from other data points in some dimensions. Without such additional clarifications, Colombier's results would likely quickly be forgotten, ignored or dismissed by those who already have made up their mind regarding the issue analyzed. Without doubt, many papers which present surprising results have been published without being cited very often, and as noted by Summers (1991), they often use elaborate econometric techniques but still fail to convince.

In this case, the application of the MM-estimator to the literature on government size and growth serves as a robustness test of the literature which has applied least squares techniques. The standard result that appear in several published papers is confirmed, leading to the conclusion that earlier findings of a negative correlation between aggregate government size and growth are not likely to be a result of a few influential outliers in the sample.

\footnotetext{
${ }^{5}$ In Bergh and Karlsson (2010), six variables are deemed robust for explaining growth in OECD countries during the 19702005 period: Total tax revenue (-), initial GDP per capita (-), inflation (-), gross savings as a share of GDP (+), labor force growth (+) and exports (+). For a survey of recent studies, see Bergh and Henrekson (2011).
} 
Finally, it is worth emphasizing that a partial correlation between aggregate government size and growth is a finding with few clear policy implications. Politicians decide on specific taxes and different expenditure projects, all with varying consequences for growth. While many studies for rich countries indicate a negative average effect of government size on growth, the question regarding how to design tax systems that minimize the negative impact on economic development remain. 


\section{References}

Afonso, A., and Furceri, D. (2010) Government size, composition, volatility and economic growth, European Journal of Political Economy, 26, pp. 517-532.

Agell, J., Ohlsson, H., and Thoursie, P.S. (2006) Growth effects of government expenditure and taxation in rich countries: A comment, European Economic Review, 50, pp. 211-219.

Bassanini, A., Scarpetta, S. and Hemmings, P. (2001) Economic growth: the role of policies and institutions. Panel data evidence from OECD countries, OECD-Economics Department Working Paper No. 283.

Bergh, A., and Henrekson, M. (2011) Government Size and Growth: A Survey and Interpretation of the Evidence. IFN working paper no. 858.

Bergh, A., and Karlsson, M. (2010) Government size and growth: Accounting for economic freedom and globalization, Public Choice, 142, pp. 195-213.

Bleaney, M., Gemmell, N., and Kneller, R. (2001) Testing the Endogenous Growth Model: Public Expenditure, Taxation, and Growth over the Long Run, Canadian Journal of Economics, 34, pp. 36-57.

Colombier, C. (2009) Growth effects of fiscal policies: an application of robust modified M-estimator, Applied Economics, 41, pp. 899-912.

Croux, C., Dhaene, G. and Hoorelbeke, D. (2008) Robust Standard Errors for Robust Estimators, mimeo, Center for Economic Studies, Discussion paper series (DPS) 03.16. Available at http://www.econ.kuleuven.ac.be/ces/discussionpapers/Dps03/Dps0316.pdf, （Accessed 13 December 2010).

Dar, A.A., and AmirKhalkhali, S. (2002) Government size, factor accumulation, and economic growth: Evidence from OECD countries, Journal of Policy Modeling, 24, pp. 679-692.

Fölster, S., and Henrekson, M. (2001) Growth effects of government expenditure and taxation in rich countries, European Economic Review, 45, pp. 1501-20.

Heston, A., Summers, R. and Bettina, A., (2009) Penn World table, version 6.3, Center for International Comparisons of Production, Income and Prices, University of Pennsylvania. Available at http://pwt.econ.upenn.edu/php_site/pwt_index.php, (Accessed 13 December 2010).

Huber, P.J. (1981) Robust Statistics. Wiley, New York. 
Kneller, R., Bleaney, M. and Gemmell, N. (1999) Fiscal policy and growth: evidence from OECD countries, Journal of Public Economics, 74, pp. 171-90.

Nijkamp, P. and Poot, J. (2004) Meta-analysis of the effect of fiscal policies on long-run growth, European Journal of Political Economy, 20, pp. 91-124.

OECD Economic Outlook No. 74 (2003).

Romero-Avila, D., and Strauch, R. (2008) Public finances and long-term growth in Europe: Evidence from a panel data analysis, European Journal of Political Economy, 24, pp. 172-91.

Rosseeuw, P. J. (1984) Least median of squares regression, Journal of the American Statistical Association, 79, 871-80.

Rosseeuw, P. J and Yohai, V. J. (1984) Robust regression by means of S-estimators. In Robust and Nonlinear Time Series (Eds.) J. Farnke, W Härdle and D. Martin. Lecture Notes in Statistics 26, Springer, New York, pp. 256-72.

Salibian-Barrera, M and Yohai V. J. (2006) A Fast Algorithm for S-Regression Estimates, Journal of Computational and Graphical Statistics, 15, pp. 1-14.

Summers, L. H. (1991) The scientific illusion in empirical macroeconomics, Scandinavian Journal of Economics, 93, pp. 129-148.

Verardi, V and Croux, C. (2009) Robust regression in Stata, The Stata Journal, 9, pp. 439-453.

Yohai, V. J. (1987) High Breakdown-Point and High Efficiency Robust Estimates for Regression, The Annals of Statistics, 15, pp. 642-656. 